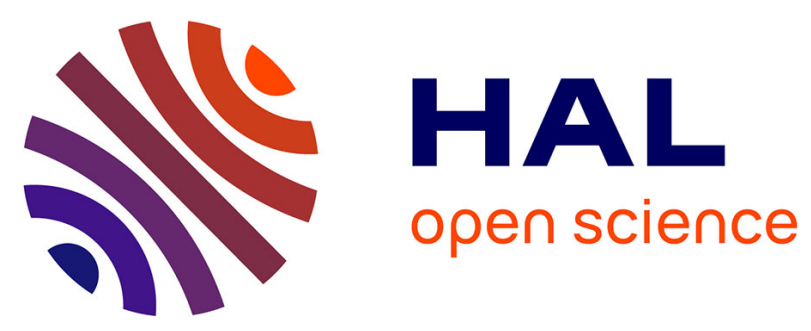

\title{
Ultrabright and Fluorogenic Probes for Multicolor Imaging and Tracking of Lipid Droplets in Cells and Tissues.
}

Mayeul Collot, Tkhe Kyong Fam, Ashokkumar Pichandi, Orestis Faklaris, Thierry Galli, Lydia Danglot, Andrey Klymchenko

\section{To cite this version:}

Mayeul Collot, Tkhe Kyong Fam, Ashokkumar Pichandi, Orestis Faklaris, Thierry Galli, et al.. Ultrabright and Fluorogenic Probes for Multicolor Imaging and Tracking of Lipid Droplets in Cells and Tissues.. Journal of the American Chemical Society, 2018, 140 (16), 10.1021/jacs.7b12817 . hal02390258

\section{HAL Id: hal-02390258 \\ https://hal.science/hal-02390258}

Submitted on 2 Dec 2019

HAL is a multi-disciplinary open access archive for the deposit and dissemination of scientific research documents, whether they are published or not. The documents may come from teaching and research institutions in France or abroad, or from public or private research centers.
L'archive ouverte pluridisciplinaire HAL, est destinée au dépôt et à la diffusion de documents scientifiques de niveau recherche, publiés ou non, émanant des établissements d'enseignement et de recherche français ou étrangers, des laboratoires publics ou privés. 


\title{
Ultrabright and Fluorogenic Probes for Multicolor Imaging and Tracking of Lipid Droplets in Cells and Tissues
}

\author{
Mayeul Collot, ${ }^{11}$ Tkhe-Kyong Fam, ${ }^{1}$ Pichandi Ashokkumar, ${ }^{1}$ Orestis Faklaris, ${ }^{2}$ Thierry Galli, ${ }^{3,4}$ Lydia \\ Danglot, ${ }^{3,4}$ Andrey S. Klymchenko ${ }^{1}$ \\ ${ }^{1}$ Laboratoire de Biophotonique et Pharmacologie, CNRS UMR 7213, Université de Strasbourg, Faculté de Pharmacie, 74, \\ Route du Rhin, 67401, Illkirch, France. \\ ${ }^{2}$ ImagoSeine core facility, Institut Jacques Monod, Université Paris Diderot/CNRS, UMR 7593, 15 rue Hélène Brion, 75205 \\ Paris CEDEX 13, France \\ ${ }^{3}$ INSERM U894 - Centre de Psychiatrie et Neurosciences, "Membrane Traffic in Health and Diseased Brain" Team, $102-$ \\ 108 rue de la santé, 75014 Paris, France \\ ${ }^{4}$ Université Paris Descartes, 75014 Paris, France
}

KEYWORDS: lipid droplets, dioxaborine, multicolor imaging, Two-Photon Excitation imaging, tissue imaging, intercellular communication.

\begin{abstract}
Lipid droplets (LDs) are intracellular lipid-rich organelles that regulate the storage of neutral lipids and were recently found to be involved in many physiological processes, metabolic disorders as well as diseases including obesity, diabetes and cancers. Herein we present a family of new fluorogenic merocyanine fluorophores based on an indolenine moiety and a dioxaborine barbiturate derivative. These so-called StatoMerocyanines (SMCy) span their fluorescence from yellow to the near infrared (NIR) in oil with an impressive fluorescence enhancement compared to aqueous media. Additionally, SMCy display remarkably high molar extinction coefficients (up to $390,000 \mathrm{M}^{-1} . \mathrm{cm}^{-1}$ ) and high quantum yield values (up to $100 \%$ ). All the members of this new family specifically stain the LDs in live cells with very low background noise. Unlike Nile Red, a well-known lipid droplet marker, SMCy dyes possess narrow absorption and emission bands in the visible thus allowing multicolor imaging. SMCy proved to be compatible with fixation and led to high quality 3D-images of lipid droplets in cells and tissues. Their high brightness allowed efficient tissue imaging of adipocytes and circulating LDs. Moreover their remarkably high two-photon absorption cross-section, especially SMCy5.5 (up to 13,300 GM) as well as their capacity to efficiently fluoresce in the NIR region led to two-photon multicolor tissue imaging (liver). Taking advantage of the available color palette, lipid droplets exchange between cells was tracked and imaged thus demonstrating intercellular communication.
\end{abstract}

\section{Introduction}

Lipid droplets (LDs), also known as adiposomes or lipid bodies, are intracellular lipid-rich organelles that regulate the storage of neutral lipids including triglycerides and cholesterol esters. ${ }^{1,2}$ Although LDs are mainly found in adipose tissue, nearly all cells are capable of storing lipids in these reservoirs, as this ability to store such a source of metabolic energy is crucial for survival. ${ }^{3,4}$ It has been shown that cells other than adipocytes can form LDs as a response to a stress. ${ }^{4}$ In the recent years, LDs draw a considerable attention as they were found to be involved in many physiological processes including membrane synthesis and trafficking, 5 , 6 protein degradation, ${ }^{7}$ but also inflammation ${ }^{8}$ and pathologies including obesity, diabetes and atherosclerosis ${ }^{9}$ as well as viral replication ${ }^{10}$ and cancer. ${ }^{11,12,13}$ Therefore, imaging and tracking LDs is of prior importance. The rise of fluorescence imaging techniques stimulated the development of efficient molecular fluorescent probes specific for various physiological phenomena or able to specifically stain organelles including mitochondria, nucleus, plasma membrane, etc. ${ }^{14151617}$ In particular, one should mention fluorogenic probes that turn on their emission only after binding to the biological target allowing background-free bioimaging. ${ }^{18} 1920{ }^{21}$ However, examples of probes for LDs are still limited. Nile Red is a commercially available solvatochromic dye (Figure 1A) that was reported to stain the $\mathrm{LDs}^{22}$ and is the most commonly used LDs marker. However, Nile Red suffers from several drawbacks: (i) non-specific staining of other organelles (particularly lipid membranes) and (ii) broad absorption and emission spectra that limit the possibilities for multicolor imaging. Although recent efforts have been made to develop new LDs probes based on various fluorophores including BODIPY $\left(496 / 503,,^{23} 540^{24}\right.$ ), AIEgens (Aggregation Induced Emission fluorophores), ${ }^{25}$ azafluorenone, ${ }^{26}$ benzothiadiazole, ${ }^{27}$ only one example of a far-red emitting LD marker was recently published. ${ }^{28}$ However the latter, based on AIEgen, suffers from broad emission spectrum emitting in both far-red and NIR regions and was used at high concentrations $(10 \mu \mathrm{M})$ probably due to its low quantum yield $(0.05)$. In 
addition to emitting at the far-red and NIR wavelength, the probe should be excitable at optical window suitable for optimal tissue penetration (670-910 nm), which can be achieved from the two-photon excitable fluorescent probes with high TPA cross section. ${ }^{29}$ Therefore, bright and selective LD probes, compatible in multicolor imaging and operating in the far-red and NIR region, are in demand. Cyanines are one of the most famous and widely used fluorophores. Their emission color spans from the visible range to the NIR and constitute a platform for biomolecule labelling ${ }^{30}$ and for the development of chemosensors for bioimaging. ${ }^{31,32}$ Among cyanines one can differentiate the cationic carbocyanines and the non-charged merocyanines (Figure 1B). Carbocyanines are bright fluorophores but their positive charge can be detrimental for designing specific fluorescent probes as it has tendency to provoke attraction towards negatively charged biomolecules (proteins and bio-membranes) by opposite charge attractions. Merocyanines circumvent this problem, as the core fluorophore generally does not display any charges. Unfortunately, in many cases merocyanine are non-photostable. Conversely, BODIPY are generally neutral, bright and stable fluorophores due to their planar structures stabilized by a difluoroboron complex that reduces the rotations and vibrations. Consequently, fluorophores including merocyanines stabilized with a rigid boron bridge (dioxaborine complex) are drawing a continuous attention in the field of bioimaging. Indeed these fluorophores served in cellular imaging either in molecular form ${ }^{33,34,35}$ or incorporated in nanoparticles, ${ }^{36,37,38}$ as well as for imaging nucleus, ${ }^{39}$ sensing oxygen ${ }^{40}{ }^{41}$ or $\mathrm{DNA}^{42}{ }^{43}$ and imaging ligand receptor interactions. ${ }^{44}$
Barbiturate-based merocyanines are known for decades. MC-540 (Figure 1B), a fluorescent probe for lipid membranes, ${ }^{45}$ is a figurehead of this family. Although it is a bright red emitting fluorophore, it suffers from a low photostability and high phototoxicity. The dioxaborine barbituryl moiety was first introduced by Zyabrev et al. and served to develop bright negatively charged dyes (Figure $1 \mathrm{~B}) .^{46}$ In parallel, fluorophores incorporating dioxaborine complexes and indolenine moieties were intensively studied by Kovtun and coworkers (Figure 1B). ${ }^{47,48,49}$

Herein, we developed a family of new merocyanine fluorophores based on an indolenine moiety and a dioxaborine barbiturate derivative separated by a polymethyne chain of various lengths (Figure 1). These so-called StatoMerocyanines (SMCy) span their fluorescence from yellow to the NIR and display a bright fluorescence due to high molar extinction coefficients and high quantum yields values. SMCy are fluorogenic as they are non-emissive in aqueous media and stain the lipid droplets of cells in a bright and selective manner. Additionally, due to their narrow absorption and emission bands, SMCy showed their efficiency in multicolor imaging compared to Nile Red and successfully served for multicolor tissue imaging. SMCy dyes were shown to possess remarkably high two-photon absorption cross-section (up to more than 10,000 GM) and were successfully used in multicolor twophoton excitation (TPE) tissue imaging. Finally we used SMCy probes to track two populations of LDs and we demonstrated that LDs exchange occurs between cells.
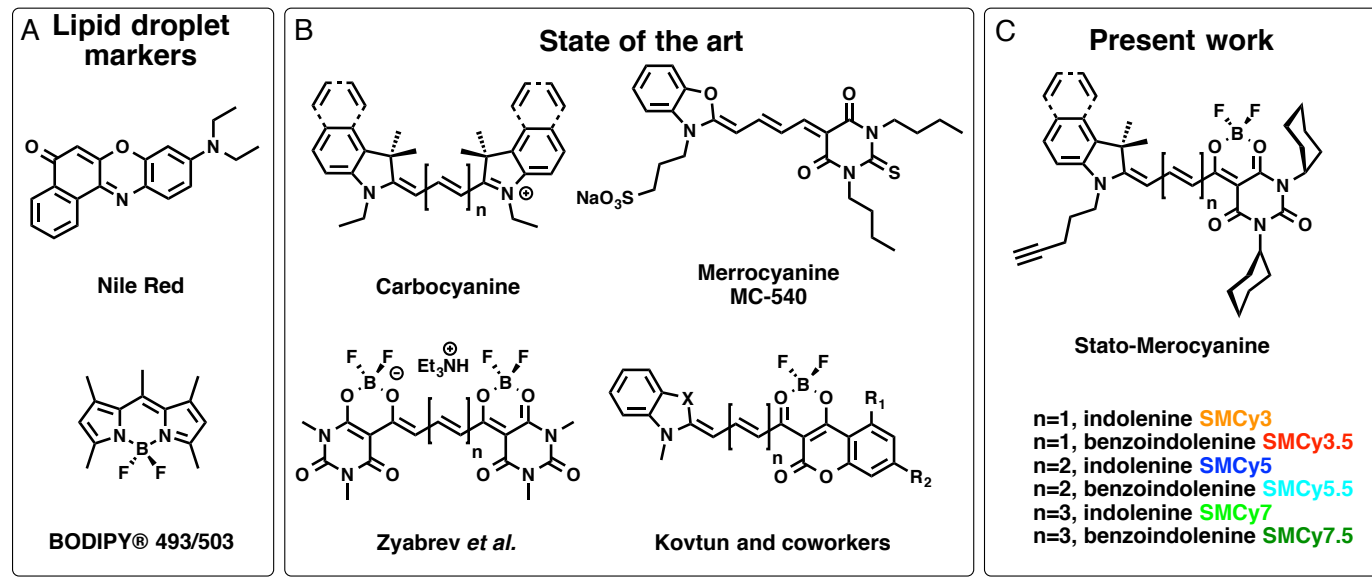

Figure 1. (A) Commonly used LDs probes. (B) Structure of various cyanines including the pioneer works on dioxaborine cyanines. (C) The six members of the StatoMerocyanines family.

\section{Results and discussion Synthesis}

Herein we introduce the SMCy fluorophores that arose from the stabilization of a barbiturate-based merocyanine by a dioxaborine bridge that fixes (stativus in latin) a degree of rotation of the fluorophore and therefore enhances its brightness (Figure 1C).

SMCy dyes are composed of: 1) an indolenine moiety bearing a pentynyl tail that reinforces the hydrophobicity and let the opportunity to functionalize the dye by the copper(I)catalyzed alkyne-azide cycloaddition (CuAAC), if needed, and 2) a dioxaborine barbituric moiety bearing two cyclohexyl rings that were chosen for their hydrophobicity and bulkiness that can help in preventing formation of non-emissive $H$ aggregates by $\pi$-stacking. ${ }^{50} 51$

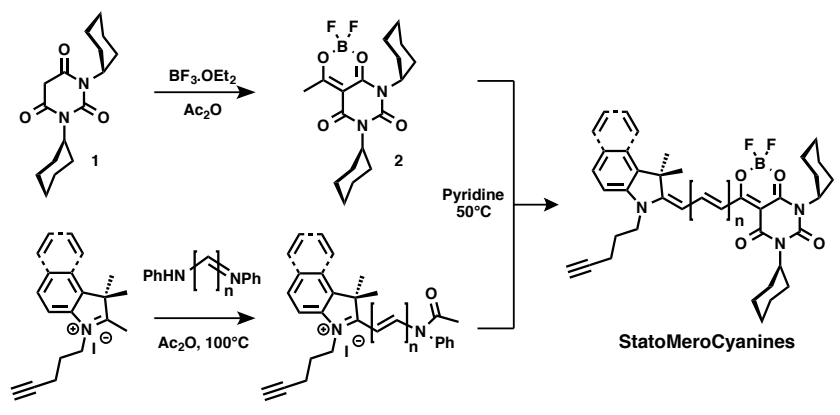

Scheme 1. Synthesis of SMCy dyes. 
The synthesis involved the acetylation of dicyclohexylbarbituric acid 1 in the presence of $\mathrm{BF}_{3} . \mathrm{OEt}_{2}$ to form the dioxaborine barbituryl 2 (Scheme 1). The latter was then condensed on hemicyanines with various polymethine chain lengths in pyridine to provide the SMCy dyes.

The same nomenclature as the one introduced by Ernst et al. for the carbocyanines, ${ }^{53}$ was used. The suffix number indicates the number of carbon separating the indole ring from the dioxaborine barbituryl and the ".5" depicts the use of the extended benzoindolenine moiety instead of indolenine (Figure 1C). The obtained fluorophores were characterized by ${ }^{1} \mathrm{H},{ }^{13} \mathrm{C}$ and ${ }^{19} \mathrm{~F}$ NMR as well as high-resolution mass spectrometry. Additionally, the structure of SMCy7 was confirmed by X-ray diffraction and showed a planar structure with minimal twist of the polymethine chain as well as the bulkiness induced by the cyclohexyl moieties (Figure 2).

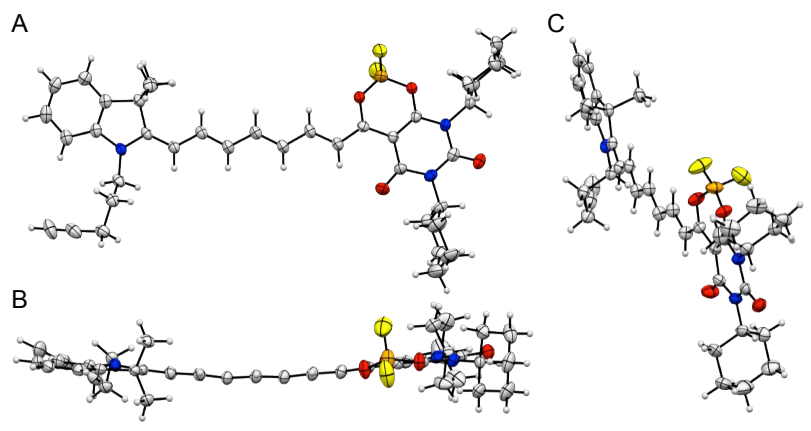

Figure 2. ORTEP representation of SMCy7 obtained by X-ray diffraction of single crystal. (A) Side view, (B) top view and (C) diagonal view. For clarity, heteroatoms were colored: Boron (orange), nitrogen (blue), oxygen (red) and fluorine (yellow).

\section{Spectroscopic studies}

The photophysical properties of SMCy dyes were first studied in ten various organic solvents with increasing polarity from toluene to DMSO and are summarized in Table 1 (all spectra are available in the Supplementary Information). First, the SMCy mostly displayed narrow absorption and emission spectra and span their absorption wavelengths from 526 to 770 $\mathrm{nm}$ and their emission wavelengths from 550 to $794 \mathrm{~nm}$ (Figure 3). The use of the benzoindolenine instead of the indolenine moiety, giving rise to the ".5" markers, typically provoked a $20 \mathrm{~nm}$ bathochromic shift in both absorption and emission spectra. All SMCy exhibited positive solvatochromism, as their absorption and emission spectra were significantly red shifted in polar solvents. Moreover, the solvatochromic effect, as well as the Stokes shift increases with the length of the polymethine chain. Indeed, whereas SMCy3 displayed only a $8 \mathrm{~nm}$ bathochromic emission shift from toluene to DMSO, SMCy7 displayed a $52 \mathrm{~nm}$ shift (Table 1). Weak solvatochromism for the dyes with shorter conjugation (SMCy3 and SMCy3.5) can be explained by their merocyanine type of electronic distribution, where electronic charge of indolenine nitrogen is transferred to barbiturate unit in the ground state without further strong change in the excited state. However, for dyes exhibiting longer conjugation this ground-state charge transfer is probably less pronounced, so that they undergo charge transfer in the excited state. The latter increases the dipole moment on electronic excitation leading to significant solvatochromism in absorption and fluorescence, in line with the earlier report on other asymmetrical cyanine dyes. ${ }^{54}$ SMCy3 and SMCy3.5 also slightly differ from the other SMCy. First, whereas hypochromism was observed with increasing solvent polarity, the other SMCy displayed hyperchromism (Figures and tables S1 to S6). Then, whereas other SMCy shorten their full width at half maximum (FWHM) with increasing solvent polarity, SMCy3 and SMCy3.5 did not display significant changes in their spectra. In addition, the brightness of SMCy is highly dependent on the nature of the solvent; they generally display high molar extinction coefficients ranging from 77,000 to an impressive value of 394,000 $\mathrm{M}^{-1} . \mathrm{cm}^{-1}$ and their quantum yields values vary from 0.07 to 0.76 (see SI). Among the SMCy dyes, SMCy5 was found to be the brightest with a maximum brightness of $227,500 \mathrm{M}^{-1} . \mathrm{cm}^{-1}$ in DCM, competing with the squaraine dyes ${ }^{55}$ and thus constituting one of the brightest small molecule to date. ${ }^{56,57}$ As mentioned earlier, the photostability of merocyanine can be a limitation for their use in bioimaging, therefore the photostability of SMCy dyes was evaluated. SMCy3 and SMCy5 were continuously irradiated in cuvette for one hour in dioxane. Their photostability were monitored and compared to fluorophores with similar spectral properties, MC-540 a barbiturate-based merocyanine and DID, a far-red emitting carbocyanine $5,^{23}$ respectively. The results showed that both SMCy3 and SMCy5 displayed higher photostability compared to the merocyanine and the carbocyanine (Figure S7).

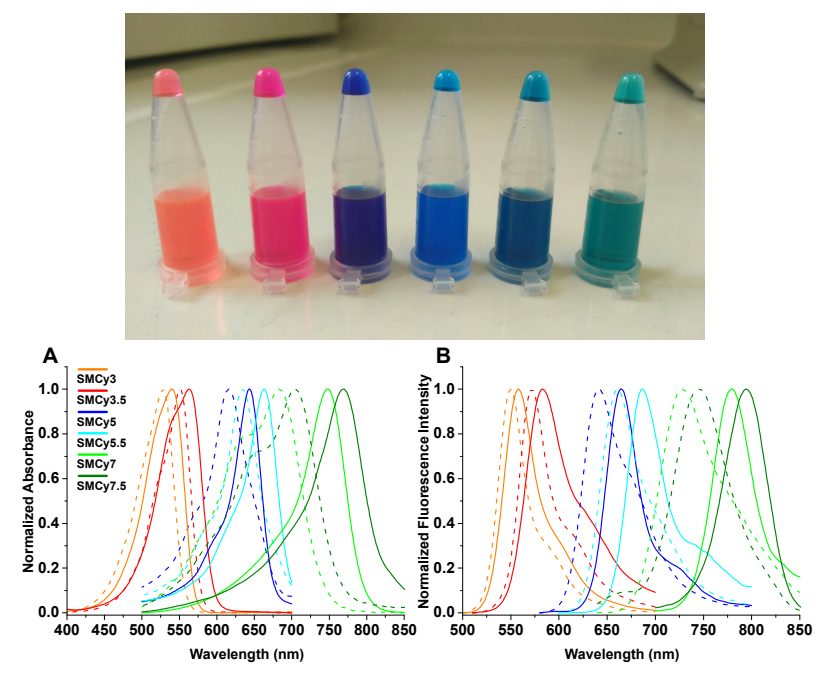

Figure 3. Top: Picture of the SMCy in solution $(200 \mu \mathrm{M}$ in DMSO). From left to right: SMCy3, SMCy3.5, SMCy5, SMCy5.5, SMCy7 and SMCy7.5. Bottom: Normalized absorption spectra (A) and normalized emission spectra (B) of $\mathrm{SMCy} 3$ to SMCy7.5 in toluene (dashed lines) and in DMSO (solid lines). Concentrations were: $1 \mu \mathrm{M}$ for SMCy3, SMCy3.5, SMCy7 and SMCy7.5 and $200 \mathrm{nM}$ for SMCy5 SMCy5.5. Excitations were $490 \mathrm{~nm}$ for SMCy3 and SMCy3.5, $560 \mathrm{~nm}$ for SMCy5, 590 for SMCy5.5, 630 for SMCy7, and 630 and $690 \mathrm{~nm}$ for SMCy7.5. 
Table 1. Photophysical properties of SMCy dyes in toluene and DMSO. ${ }^{\mathrm{a}}$

\begin{tabular}{cccccccccc}
\hline Probe & Solvent & $\begin{array}{c}\lambda_{\text {Abs }} \\
(\mathrm{nm})\end{array}$ & $\begin{array}{c}\varepsilon \\
\left(\mathrm{M}^{-1} \cdot \mathrm{cm}^{1}\right)\end{array}$ & $\begin{array}{c}\mathrm{FWHM}_{\text {Abs }} \\
(\mathrm{nm})\end{array}$ & $\begin{array}{c}\lambda \mathrm{Em} \\
(\mathrm{nm})\end{array}$ & $\begin{array}{c}\mathrm{FWHM}_{\mathrm{Em}} \\
(\mathrm{nm})\end{array}$ & $\begin{array}{c}\text { Stokes } \\
\text { shift }\end{array}$ & $\begin{array}{c}\text { QY } \\
(\phi)\end{array}$ & $\begin{array}{c}\text { Brightness } \\
(\varepsilon \times \phi)\end{array}$ \\
\hline \multirow{2}{*}{ SMCy33 } & Toluene & 528 & 94,000 & 52 & 550 & 33 & 22 & 0.3 & 28,200 \\
& DMSO & 540 & 77,300 & 57 & 558 & 40 & 18 & 0.37 & 28,600 \\
SMCy3.5 & Toluene & 551 & 124,000 & 51 & 572 & 37 & 21 & 0.68 & 84,320 \\
& DMSO & 563 & 110,000 & 64 & 583 & 56 & 20 & 0.18 & 19,800 \\
SMCy5 & Toluene & 615 & 203,000 & 61 & 642 & 63 & 27 & 0.35 & 71,000 \\
& DMSO & 644 & 363,000 & 42 & 665 & 39 & 21 & 0.42 & 152,400 \\
SMCy5.5 & Toluene & 634 & 168,000 & 52 & 661 & 53 & 27 & 0.65 & 109,200 \\
& DMSO & 663 & 241,200 & 50 & 687 & 44 & 24 & 0.26 & 62,700 \\
SMCy7 & Toluene & 683 & 109,000 & 114 & 727 & 84 & 44 & 0.21 & 22,890 \\
& DMSO & 748 & 231,000 & 67 & 779 & 49 & 31 & 0.33 & 76,230 \\
SMCy7.5 & Toluene & 705 & 89,000 & 116 & 746 & 67 & 41 & 0.18 & 16,020 \\
& DMSO & 770 & 183,000 & 78 & 794 & 53 & 24 & 0.18 & 32,900
\end{tabular}

${ }^{\text {a }} \varepsilon$ is the molar extinction coefficient, FWHM is the full width at half maximum and the Stokes shifts are expressed in nm.

In the light of the high lipophilic nature of the SMCy dyes, their photophysical properties were measured in oils: Colza oil (mainly composed of unsaturated long chain triglycerides) and in labrafac ${ }^{\mathrm{TM}}$ (a medium chain triglycerides containing oil) as well as in water. The results showed first that despite their high lipophilic nature, SMCy can be suspended in water: their significantly broadened absorption spectra suggest that they actually form soluble aggregates (Figure 4A and Figure S12 and S13). Consequently, SMCy are non-emissive in water (Figure 4B). In oils, SMCy dyes display high brightness similar or higher than the ones obtained in non-polar solvents, thus providing impressive fluorescence enhancements (up to 1,700fold) compared to water (Table 2). It is also noteworthy that, in these lipophilic environments, all the SMCy dyes are efficiently excited with the commonly available lasers $(488,560$ and $630 \mathrm{~nm}$ ). Remarkably, SMCy5 and SMCy5.5 exhibit the highest brightness, especially in labrafac reaching high quantum yields 0.74 and 1.00 respectively. Higher quantum yields of SMCy in oils compared to organic solvents could be linked to additional restriction of intramolecular rotation in viscous media, in line with a previous report on a push-pull dioxaborine derivative. ${ }^{44}$ The photostability in oil of SMCy3 and SMCy5 was compared to commercially available LDs markers, namely BODIPY $493 / 503$ and Nile Red. Whereas
BODIPY 493/503 and SMCy5 lost 15\% of fluorescence intensity after $1 \mathrm{~h}$ irradiation in cuvette, SMCy3 displayed high photostability similar to Nile Red (Figure S8). According to the present results, SMCy appeared as suitable candidates to probe neutral lipophilic environments such as LDs in cells, using fluorescence microscopy techniques.

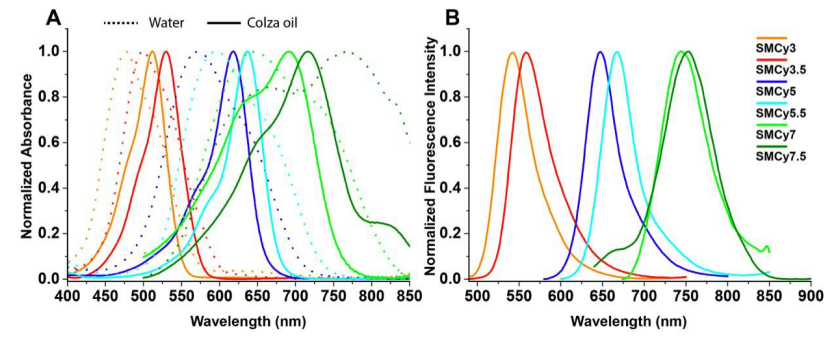

Figure 4. Normalized absorption spectra of SMCy dyes $(1 \mu \mathrm{M})$ in water (dashed lines) and in colza oil (solid lines) (A) and their normalized emission spectra in oil (B). Excitation wavelength was: $480 \mathrm{~nm}$ for SMCy3 and SMCy3.5, $560 \mathrm{~nm}$ for SMCy5, 590 $\mathrm{nm}$ for SMCy5.5, and $630 \mathrm{~nm}$ for SMCy7 and SMCy7.5

Table 2. Photophysical properties of StatoMerocyanines in triglycerides oils. ${ }^{\text {a }}$

\begin{tabular}{ccccccccc}
\hline & Solvent & $\begin{array}{c}\lambda_{\text {Abs }} / \lambda_{\text {Em }} \\
(\mathrm{nm})\end{array}$ & $\begin{array}{c}\text { Stokes } \\
\text { Shift }(\mathrm{nm})\end{array}$ & $\begin{array}{r}\varepsilon \\
\left(\mathrm{M}^{-1} \cdot \mathrm{cm}^{-1}\right)\end{array}$ & $\begin{array}{c}\text { FWHM } \\
\text { Abs/Em } \\
(\mathrm{nm})\end{array}$ & $\begin{array}{c}\text { QY } \\
(\phi)\end{array}$ & $\begin{array}{c}\text { Brightness } \\
(\varepsilon \times \phi)\end{array}$ & $\Delta \mathrm{F} / \mathrm{F}_{0}$ \\
\hline \multirow{2}{*}{ SMCy3 } & Colza oil & $512 / 541$ & 29 & 82,900 & $54 / 49$ & 0.21 & 17409 & 423 \\
& labrafac & $511 / 542$ & 31 & 87,300 & $55 / 51$ & 0.25 & 21825 & 515 \\
SMCy3.5 & Colza oil & $530 / 559$ & 29 & 100,000 & $57 / 55$ & 0.40 & 40000 & 674 \\
& labrafac & $529 / 557$ & 28 & 108,000 & $57 / 58$ & 0.54 & 58320 & 827 \\
SMCy5 & Colza oil & $618 / 648$ & 30 & 256,000 & $54 / 46$ & 0.60 & 153600 & 1088 \\
& labrafac & $617 / 644$ & 27 & 270,000 & $54 / 49$ & 0.74 & 199800 & 1700 \\
SMCy5.5 & Colza oil & $638 / 662$ & 24 & 169,000 & $52 / 42$ & 0.74 & 125060 & 1535 \\
& labrafac & $636 / 660$ & 24 & 194,000 & $52 / 43$ & 1.00 & 194000 & 1535 \\
SMCy7 & Colza oil & $692 / 744$ & 52 & 44,000 & $134 / 75$ & 0.42 & 18480 & 55 \\
& labrafac & $687 / 735$ & 48 & 44,000 & $137 / 84$ & 0.44 & 19360 & 79 \\
SMCy7.5 & Colza oil & $716 / 753$ & 37 & 103,000 & $125 / 71$ & 0.19 & 19570 & 203 \\
& labrafac & $712 / 743$ & 31 & 83,000 & $132 / 74$ & 0.2 & 16600 & 145
\end{tabular}

${ }^{\text {a }}$ Concentration of the dyes was $1 \mu \mathrm{M} . \Delta \mathrm{F} / \mathrm{F}_{0}$ is the fluorescence enhancement between oil and water. $\mathrm{F}_{0}$ is the maximum fluorescence intensity in water. 


\section{Cellular experiments \\ Localization of SMCy}

On the basis if their chemical properties described above, SMCy were incubated with KB cells (HeLa cells derivatives) and the fluorescence was monitored over the time. After several minutes of incubation in a starvation medium (HBSS), a selective and intense fluorescence was observed in vesicles slowly moving in the cytoplasm of the cells (see movie 1). The slow motion of these vesicles as well as their size and spherical shape led us to think that it was LDs. In order to confirm our expectations, a colocalization experiment was performed using Nile Red as a reference LDs marker. As mentioned, Nile Red is a solvatochromic fluorophore with broad emission spectra and therefore can hardly be used for colocalization experiments with green and red emitting fluorophore due to crosstalk between the imaging channels. Thus, after checking that cross talk did not occur in the NIR channel (excitation at $635 \mathrm{~nm}$ ) (Figure S9), SMCy7 that emits in the NIR $(730 \mathrm{~nm})$ was first colocalized with Nile Red (Figure 5A). The results confirmed a clear colocalization between Nile Red and SMCy7. Consequently SMCy7 was used in combination with SMCy3 and SMCy3.5 (Figure 5B and C) and SMCy3 was then used to colocalize with SMCy5 and SMCy5.5 (Figure 5D and E). These experiments confirmed that the SMCy dyes selectively mark the LDs. In order to investigate the mechanism of staining, images have been taken at various times of incubation on live and fixed cells. The results showed a fluorescence enhancement in the LDs over the time in both cells (see Figure S10). Consequently, we assume that SMCy accumulate in the LDs in a passive manner. The SMCy were also compared to BODIPY 493/503. Although SMCy dyes require incubation at $37^{\circ} \mathrm{C}$, BODIPY $493 / 503$ immediately stained the LD after addition (Figure S11). After investigating, we discovered that BODIPY 493/503 did not aggregate in water at concentration as high as $1 \mu \mathrm{M}$ with a quantum yield of 1.0 . In sharp contrast, the turn-on SMCy LD sensors are nonfluorescent in water due to aggregation in form of soluble nanoparticles even at $100 \mathrm{nM}$ concentration (Figure S12 and S13). Additionally, BODIPY 493/503 was shown to be less selective (Figure S14 and S15) and less photostable than SMCy3 (Figure S16). At this stage of our work, cytotoxicity studies (MTT assay) were performed and the results showed that at concentrations up to $5 \mu \mathrm{M}$, the SMCy did not lead to any significant cytotoxicity (Figure S17).

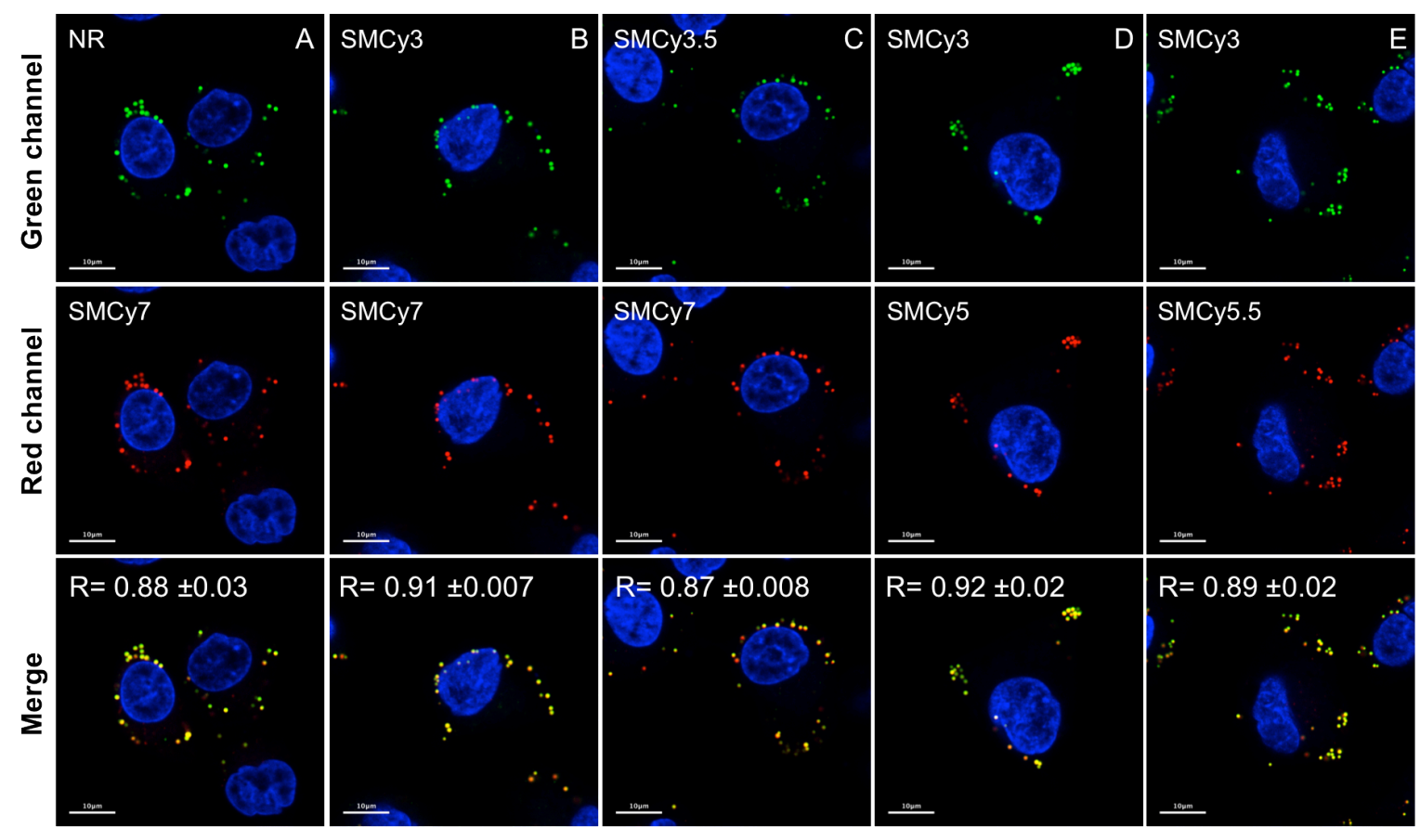

Figure 5. Laser scanning confocal microscopy of live KB cells incubated for $3 \mathrm{~h}$ in opti-MEM in the presence of fluorophores (500 $\mathrm{nM}$ ). NR is Nile Red. Hoechst ( $5 \mu \mathrm{g} / \mathrm{mL}$ ) was used to stain the nucleus (blue). Green channel: excitation at $488 \mathrm{~nm}$, emission collected: $500-600$ $\mathrm{nm}$; red channel (middle images) excitation at $635 \mathrm{~nm}$, emission collected: $645-800 \mathrm{~nm}$. The merge images correspond to the combined green and red channels. The displayed Pearson's correlation coefficient, that denotes the goodness of colocalization, is the average of at least 5 different images. Scale bar is $10 \mu \mathrm{m}$. 


\section{D imaging}

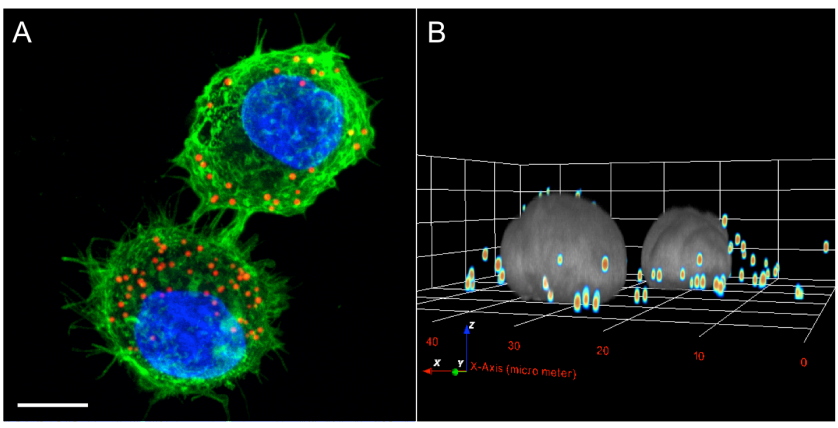

Figure 6. Images of $\mathrm{KB}$ cells incubated with SMCy5 (500 nM) then fixed (PFA 4\%) obtained by a $21 \mu \mathrm{m}$ depth Z-stack (300 nm stepwise) showing the repartition of the LDs within the cells. (A) Maximum intensity projection image displaying the LDs (red), the nucleus (blue) and the plasma membrane (green). B. 3D image displaying the LDs (colored spots) and the nucleus (gray). The nucleus was stained with $5 \mu \mathrm{g} / \mathrm{mL}$ Hoechst, the plasma membrane with MemBright-488 (200 nM). Incubation with SMCy5 was made in opti-MEM for $3 \mathrm{~h}$. Scale bar is $10 \mu \mathrm{m}$.

$3 \mathrm{D}$ imaging with confocal microscopy is normally obtained by reconstruction of Z-stack images and therefore it involves multiple laser scans of the sample leading to the photobleaching of the fluorophores. Therefore, high brightness and photostability of the fluorescent markers are required to obtain good-quality 3D images. Here, SMCy allowed 3D imaging of the LDs, revealing their subcellular localization in KB cells (Figure 6). In these experiments a $21 \mu \mathrm{m} \mathrm{Z}$-stack was performed using 70 slices with 3 averaged acquisitions per slice, representing 210 scans per image. The 3D images displayed clear and bright spots (see movie 2). Although SMCy7 and SMCy7.5 emit in the NIR region where the sensitivity of the microscope's detectors is lowered, they led to excellent 3D imaging due to the efficient excitation with the $635 \mathrm{~nm}$ laser (Figure S18).

\section{Multicolor imaging}
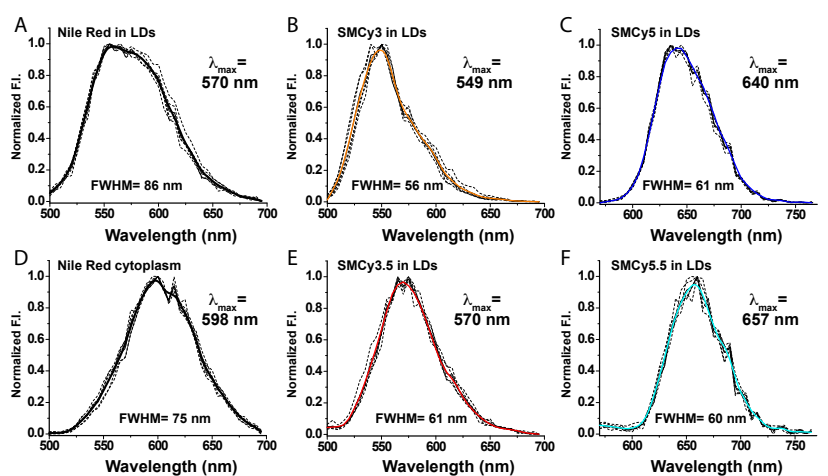

Figure 7. Normalized emission spectra of Nile Red in LDs (A) and in the cytoplasm (D) and normalized emission spectra of SMCy dyes in LDs obtained by lambda scan (5 $\mathrm{nm}$ steps) with a laser confocal microscope using the $488 \mathrm{~nm}$ laser (for Nile Red, SMCy3 and SMCy3.5) and the $560 \mathrm{~nm}$ laser (for SMCy5 and SMCy5.5). Dash lines correspond to five independent measurements (normalized), which were averaged and smoothed (solid lines).

Multicolor imaging provides important information and allows revealing different cellular processes on the same image. For this reason, it is of great importance to have available fluorescent markers with various excitation and emission wavelengths combined with narrow emission bands thus allowing their concomitant use. Lambda-scan experiment with help of a laser scanning confocal microscope allowed us to obtain in situ emission spectra of Nile Red and the SMCy in the cell lipid droplets (Figure 7). It is noteworthy that unlike Nile Red, which was bright enough in the cytosplasm to provide a lambda scan emission spectrum (Figure 7D), SMCy dyes, due to their selective LDs staining did not provide any spectrum. The obtained spectra were similar to those obtained in oil using a fluorometer confirming the localization of the dyes in nonpolar lipophilic environment. In cell lipid droplets the SMCy displayed significantly narrower spectra than Nile Red $\left(\lambda_{\mathrm{Em}}\right.$ $\max =570 \mathrm{~nm} ; \mathrm{FWHM}=86 \mathrm{~nm})$.
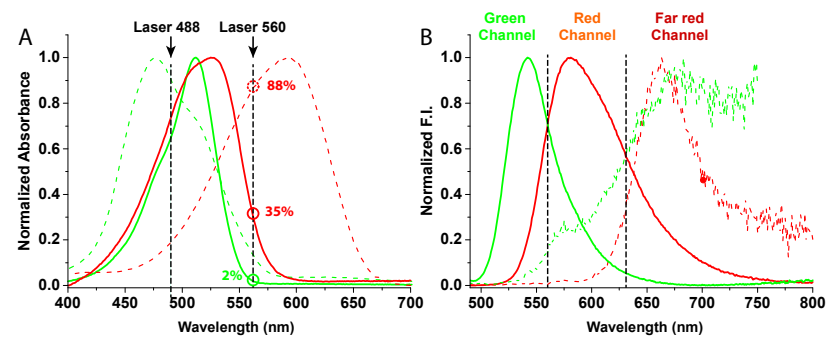

Figure 8. Normalized Absorption (A) and emission (B) spectra of SMCy3 (green lines) and Nile Red (red lines) in colza oil (solid line) and in water (dashed lines). Concentration was $1 \mu \mathrm{M}$ and excitation was $480 \mathrm{~nm}$

For these reasons, we assumed that unlike Nile Red, SMCy might be efficient in multicolor imaging. First, according to the obtained spectroscopic data in oil, we show that unlike Nile Red, SMCy3 can be used as a green LDs marker and in combination with red emitting fluorophores (Figure 8). Although both Nile Red and SMCy3 are efficiently excited with a $488 \mathrm{~nm}$ laser (70\% and $62 \%$ respectively), SMCy3 displays much narrower absorption and emission bands (FWHM: Abs $54 \mathrm{~nm}$, Em: $49 \mathrm{~nm})$, with a blue shifted emission $\left(\lambda_{\text {Em max }} 541\right.$ $\mathrm{nm})$, compared to Nile Red ( $\lambda_{\text {Em max }} 581 \mathrm{~nm}$, FMWH: Abs 80 $\mathrm{nm}, \mathrm{Em} 84 \mathrm{~nm})$. Moreover, Nile Red is also efficiently excited with the $560 \mathrm{~nm}$ laser (35\% in oil) whereas SMCy3 is only excited at $2 \%$. Finally, due to its solvatochromism, Nile Red when irradiated at $560 \mathrm{~nm}$ in water is efficiently excited $(88 \%$, Figure 8). Consequently, when Nile Red localizes in more polar cellular environments in the cytoplasm, its excitation and emission spectra shift to the red thus leading to crosstalk in the red and far-red channels. 


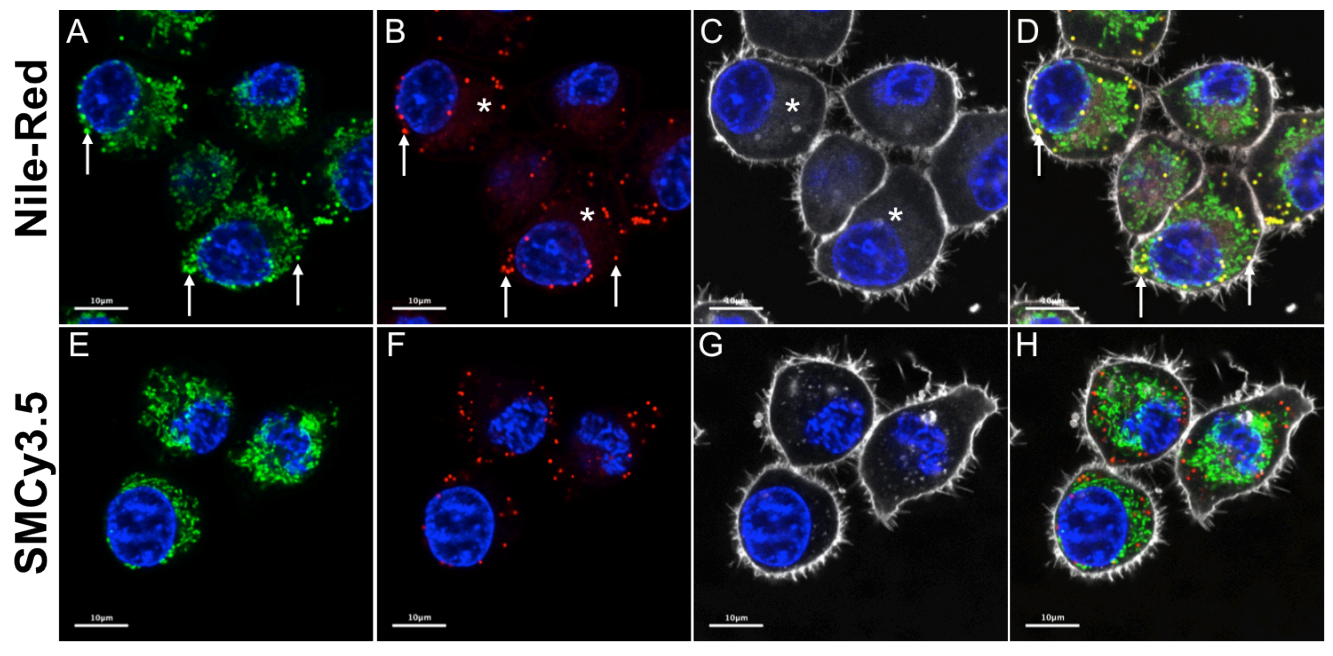

Figure 9. Laser scanning confocal microscopy images of live KB cells incubated $3 \mathrm{~h}$ with Hoechst (5 $\mu \mathrm{g} / \mathrm{mL}$, blue color), Mito-tracker ${ }^{\circledR}$ Green (200 nM), Nile Red or SMCy3.5 (500 nM). Plasma membrane was stained prior to imaging with dSQ12S a far-red emitting plasma membrane probe (gray color). Green channel: A and E (ex: $488 \mathrm{~nm}$, em: 498-540 nm); Red channel B and F (ex: 561 nm, em: 570-640 $\mathrm{nm}$ ); Far-red channel C and G (ex: $632 \mathrm{~nm}$, em: 640-750 nm). D and H are the merge of A, B, C and E, F, G respectively. White arrows and white stars indicate the crosstalk of Nile Red in the green and the far-red channels respectively. Scale bar is $10 \mu \mathrm{m}$.

As green-emitting LDs probe was available (BODIPY $493 / 503),{ }^{23}$ we then wanted to show that SMCy3.5 could be used as a red LDs marker in multicolor imaging. To this aim, KB cells were incubated with: (1) Hoechst, a blue marker for nucleus; (2) Mitotracker green, a green marker for mitochondria $^{23}$ and (3) Nile Red or SMCy3.5, as red emitting LDs markers. Prior to the imaging, dSQ12S was used as a far red plasma membrane marker. ${ }^{55}$ The obtained multicolor imaging showed that whereas Nile Red displayed distinct crosstalk in the green channel (LDs) and in the far red channel (cytoplasm), SMCy3.5 due to its sharp absorption and emission bands and its weak solvatochromism displayed no crosstalk thus leading to clear multicolor imaging (Figure 9). This set of experiment showed that unlike Nile Red, SMCy3 and SMCy3.5 can be used as green and red lipid droplet markers respectively with no crosstalk in fluorescent microscopy imaging.

\section{Tissue imaging \\ Mono-photon imaging}

Taking advantage of the brightness and specificity of the SMCy dyes, we investigated on their ability to reveal lipid rich structures/organelles in multicolor tissues imaging. For this purpose white adipose tissue of a mouse was incubated in the presence of Hoechst (nuclear staining), MemBright-488 (plasma membrane staining) and SMCy3.5. The tissue was then imaged by fluorescence microscopy (Figure 10). The obtained images allowed for 3D imaging (see movie 3 ) as well as projection that clearly shows that SMCy3.5 selectively stained the fat reservoirs of adipocytes (Figure 10B) but also revealed the presence of dots in the blood vessel that could be identified as LDL or circulatory LDs (Figure 10D).
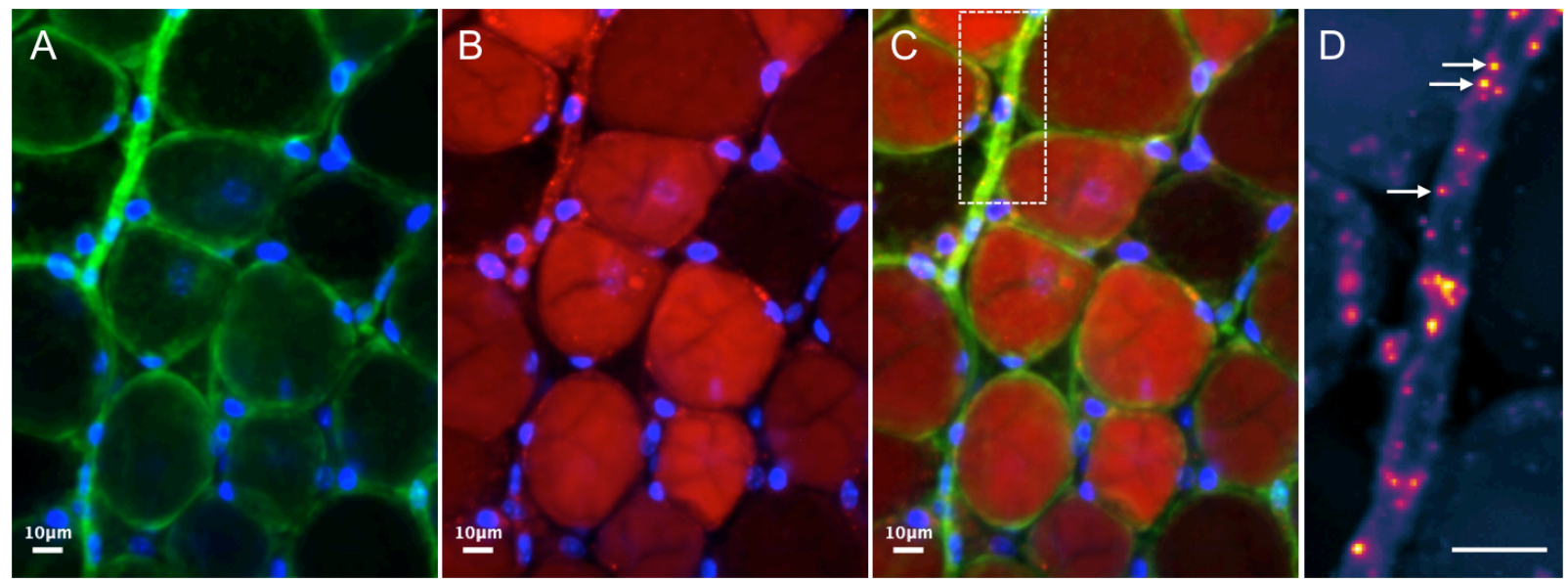

Figure 10. Images of adipocytes in mouse adipose tissue ( $25 \mu \mathrm{m}$ depth) obtained by a maximum projection of a Z-stack (100 slices of 250 $\mathrm{nm}$ depth each). The tissue was incubated overnight at $4^{\circ} \mathrm{C}$ with Hoechst $(5 \mu \mathrm{g} / \mathrm{mL}$, nuclei in blue color), (A) MemBright-488 (5 $\mu \mathrm{M}$, plasma membrane in green color) and (B) SMCy3.5 (5 $\mu \mathrm{M}$, lipid domains, red color). $\mathrm{C}$ is the merged channels. D is the zoomed ROI in C showing the lipid rich vesicles (white arrows) in the blood vessel. Scale bar is $10 \mu \mathrm{m}$. 


\section{TPE imaging}

Two-photon excitation (TPE) microscopy imaging has received considerable attention as an advanced optical technique in the field of bioimaging for several reasons.$^{58,59,60}$ First, TPE microscopy inherently provides three-dimensional sectioning since the excitation occurs only at the focal point of the sample. In addition, due to its localized excitation with a NIR laser, it reduces the photobleaching, the phototoxicity, and the cell auto-fluorescence. It also ensures deeper tissue penetration, which enables experiments on thicker live samples. For these reasons, there is a high demand for bright fluorescent probes with high TPE cross section values leading to on-going efforts to design such fluorophores. ${ }^{61}$ To this aim, we first measured the TPA cross-section of SMCy dyes in cuvette. The two-photon nature of the absorption process was verified from the quadratic dependence of the observed emission intensity $v s$ excitation power (Figure S19 to S22).

The results showed that although SMCy7 and SMCy7.5 did not display TPE below $900 \mathrm{~nm}$, the remaining dyes displayed higher TPA cross section values (Figure 11) when compared to the known LDs probes. ${ }^{29}$ While SMCy3 only possessed a modest TPA cross-section (178 $\mathrm{GM}$ at $690 \mathrm{~nm}$ ), SMCy3.5 reaches values as high as 2,400 GM (at $760 \mathrm{~nm}$ ). Finally, SMCy5 and SMCy5.5 displayed impressive TPA cross-section values, 6,250 $\mathrm{GM}$ at $740 \mathrm{~nm}$ and 13,330 $\mathrm{GM}$ at $770 \mathrm{~nm}$ respectively.
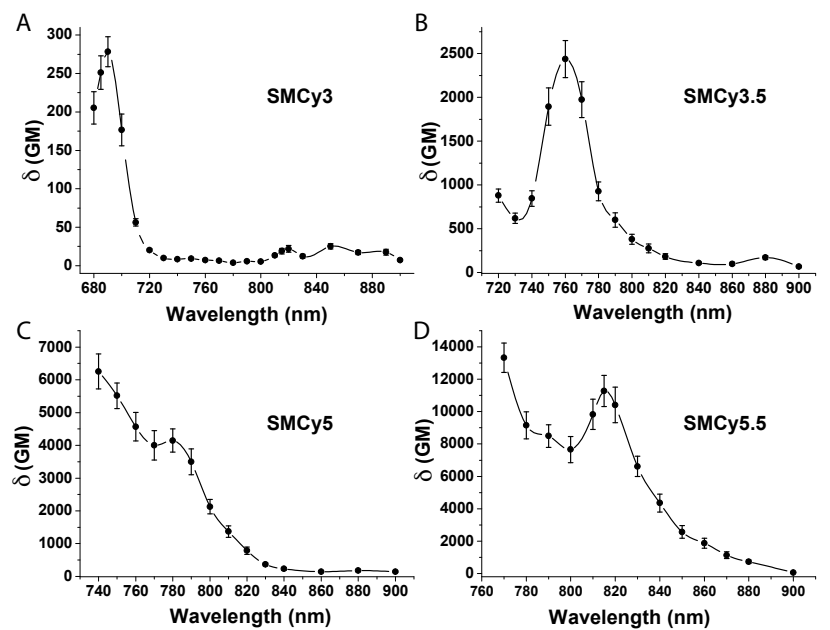

Figure 11. Two-photon excitation cross-section spectra of SMCy dyes in DMSO. The reference used for measurements was rhodamine B. GM is Goeppert-Mayer unit.

Interestingly, SMCy5.5 displays a very high cross-section values of $10,400 \mathrm{GM}$ at the commonly used $820 \mathrm{~nm}$ wavelength (used for rhodamine-based probes), combined to its exceptional brightness in lipidic environments, this probe constitutes one of the brightest two-photon excitable fluorophores to date.

In the light of the exceptional TPE brightness of SMCy, we underwent to map the lipophilic environment in tissue using multicolor TPE imaging. A mouse liver slice was incubated with Hoechst and SMCy5.5. Using only one excitation wavelength $(810 \mathrm{~nm})$, we obtained a $52 \mu \mathrm{m}$ depth 3D image where the nuclei, the lipid droplets as well as the collagen fibers (using second harmonic generation ${ }^{62,}{ }^{63}$ ) were clearly distinguished (Figure 12). The image revealed large lipid rich vesicles that are not present in the collagen rich region.

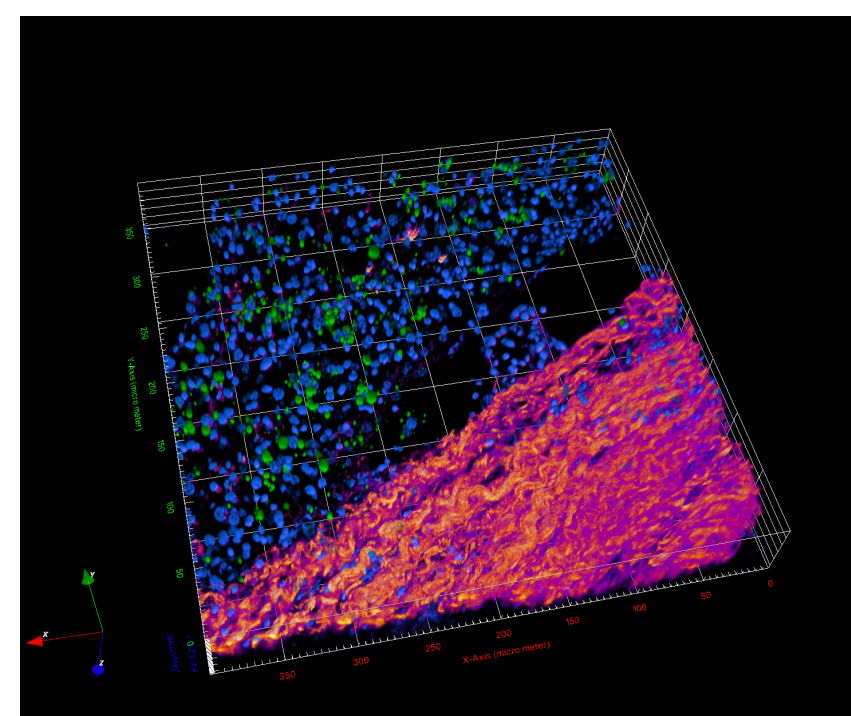

Figure 12. Two-photon excitation 3D imaging ( $52 \mu \mathrm{m}$ depth) of a mouse liver slice, incubated with Hoechst $(5 \mu \mathrm{g} / \mathrm{mL})$ and SMCy5.5 $(5 \mu \mathrm{M})$. The nuclei are displayed in blue, the lipid droplets in green and the collagen fibers in fire. Two-photon excitation wavelength was $810 \mathrm{~nm}$.

\section{Lipid droplet exchange}

With multicolor LDs markers in hand it becomes possible to monitor the fate of different LDs population in the same experiment. First, as a control experiment, a batch of KB cells was incubated with the same concentration of SMCy3.5 and SMCy5.5 for $3 \mathrm{~h}$. The images showed a strong colocalization of the dyes within the same LDs showing indifferent uptake of the dyes (Figure 13A). It is noteworthy that although almost no green LDs were detected, some red LDs were observed. This might be attributed to the Forster Resonance Energy Transfer (FRET) phenomenon occurring in some LDs and driven by the close proximity between the donor SMCy3.5 and the acceptor SMCy5.5. Second, two batches of KB cells were independently incubated with SMCy3.5 and SMCy5.5 for $3 \mathrm{~h}$. After several washing steps to avoid cross contamination, the cells were trypsinized, mixed, plated and co-cultured. After 12 $\mathrm{h}$, two distinct populations of cells could be identified by the color of their lipid droplets with no apparent exchange of LDs between cells showing no colocalization of the dyes (Figure 13B). This tends to prove that the dyes are confined in the LDs with no leakage out of the cells. After $48 \mathrm{~h}$, the same sample of cells was visualized. Remarkably, within some cells, LDs of two distinct colors were observed (Figure 13C and D), suggesting LDs exchange between cells. In these cells the colocalization of the two dyes was also minimal, proving that the dyes were not exchanged within the LDs of the same cell. These experiments illustrate that $\mathrm{KB}$ cells are able to actively exchange LDs or that cells are able to uptake LDs released from dead cells. Owning to their photostability, brightness and ability to remain in the LDs with no leakage, SMCy dyes constitute a robust tool to stain and track LDs in bioimaging experiments. 

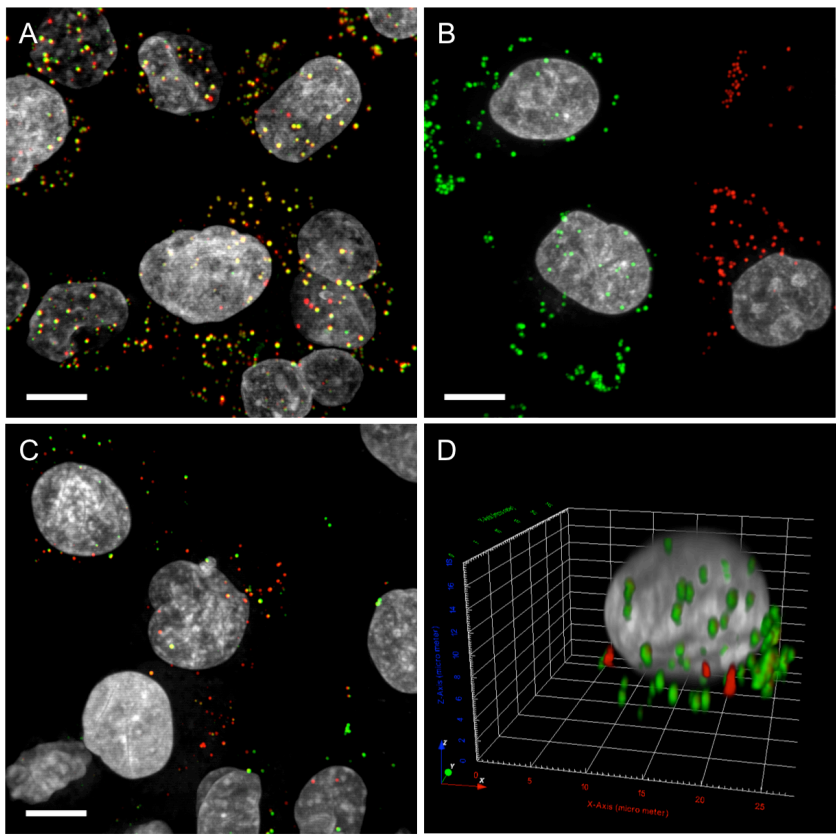

Figure 13. Images of live KB cells obtained by a maximum projection of a $20 \mu \mathrm{m}$ depth Z-stack. (A) Co-incubation of SMCy3.5 $(1 \mu \mathrm{M})$ and SMCy5.5 $(1 \mu \mathrm{M})$ for $3 \mathrm{~h}$ then imaged after $18 \mathrm{~h}$. (B) Co-culture of $\mathrm{KB}$ cells incubated with SMCy3.5 and SMCy5.5 separately after $18 \mathrm{~h}$. (C) Co-culture of KB cells incubated with SMCy3.5 and SMCy5.5 separately after $48 \mathrm{~h}$. (D) 3D view of a KB cell displaying LDs from another cell. Scale bar is $10 \mu \mathrm{m}$

\section{Functionalization of SMCy}

A
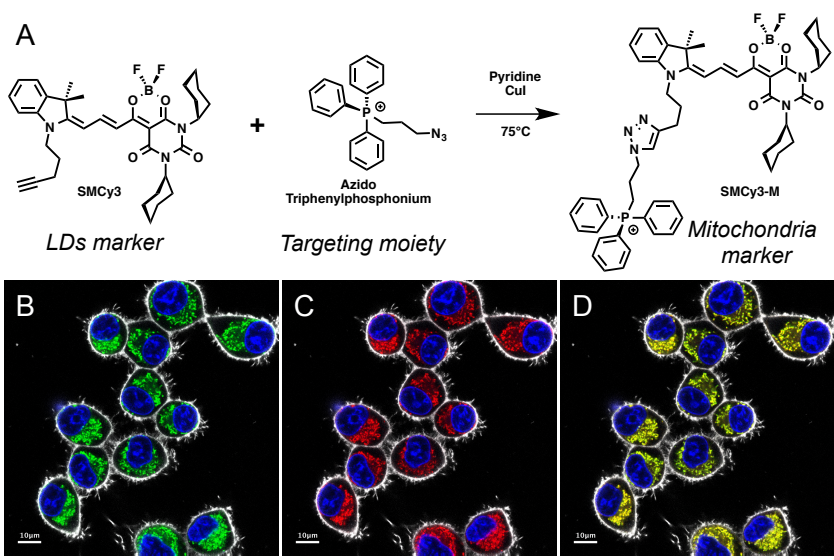

Figure 14. Synthesis of SMCy3-M by CuAAC click chemistry (A). Laser scanning confocal microscopy of live KB cells incubated for $1 \mathrm{~h}$ with Hoechst ( $5 \mu \mathrm{g} / \mathrm{mg}$, blue color) and $200 \mathrm{nM}$ of SMCy3-M (B) and Mito Tracker Red CMXRos (C). D is the merged images. The plasma membrane was stained with dSQ12S $(20 \mathrm{nM})$ prior to imaging. Excitation wavelength and emission range for imaging in $\mathrm{nm}$ : Hoechst $(405,415-470)$, SMCy3-M (488, 498-560), Mito Tracker Red (561, 571-620), and dSQ12S $(635,645-700)$. Scale bar is $10 \mu \mathrm{m}$.

SMCy dyes bear an alkyne side arm for further functionalization by CuAAC click chemistry. Indeed, owing to their interesting physicochemical properties (neutral fluorophores, high brightness, narrow absorption and emission bands) SMCy can serve as a platform to develop various selective markers or sensors. As an example, SMCy3 was involved in a click chemistry reaction with a azido triphenylphosphonium cation that is known to target mitochondria (Figure 14A). ${ }^{64}$ The obtained SMCy3-M was then incubated for $1 \mathrm{~h}$ at $200 \mathrm{nM}$ in the presence of $\mathrm{KB}$ cells. After checking that crosstalk did not occurred (Figure S23), the colocalization experiment using MitoTracker ${ }^{\mathrm{TM}}$ red led to a measured Pearson correlation coefficient of 0.96 thus proving that SMCy3 was successfully converted into an efficient and selective mitochondria marker (Figure 14).

\section{Conclusion}

In this work we designed and synthesized a new family of dioxaborine containing-merocyanines, named StatoMerocyanine (SMCy). These fluorophores cover the visible spectrum and the NIR region with high brightness and photostability. SMCy were found to be soluble in both water and oil and exhibit an impressive fluorescence enhancement between these two environments. When incubated with cells, SMCy selectively stain the LDs in a bright and background-free manner thus leading to high quality images including multicolor 3D images. Owning to their sharp absorption and emission bands, SMCy were shown to be efficient for multicolor imaging (4 colors) more particularly in the green and red channels where Nile Red leads to crosstalk. SMCy served in multicolor tissue imaging where it successfully probed the lipophilic environment in adipocytes as well as revealed circulating lipidic vesicles in the blood vessel. SMCy3 to SMCy5.5 are two-photon excitable, displaying impressive cross-section values up to 13,300 GM making SMCy5.5 one of the brightest TPE fluorophore to date. These properties allowed obtaining multicolor TPE 3D-images revealing the distribution of lipidic vesicles in liver tissue. Benefiting from the different available colors of these LDs marker, we used them to track two populations of LDs and showed that LDs exchange occurs between cells. Finally, we demonstrated that using their alkyne group, SMCy can be derivatized by click chemistry in order to obtain fluorescent probes with different targeting specificity. This study should encourage the continuation in the development of new dioxaborine merocyanines for bioimaging.

\section{Materials and methods}

\section{Synthesis}

All starting materials for synthesis were purchased from Alfa Aesar, Sigma Aldrich or TCI Europe and used as received unless stated otherwise. NMR spectra were recorded on a Bruker Avance III $400 \mathrm{MHz}$ spectrometer. Mass spectra were obtained using an Agilent Q-TOF 6520 mass spectrometer. Synthesis of all new compounds is described in supporting information.

\section{Spectroscopy}

The water used for spectroscopy was Milli-Q water (Millipore), all the solvents were spectro grade. Colza oil, mainly composed of unsaturated lipids $\sim 93 \%$ was obtained from Lesieur (Asnières-sur-Seine, France). Labrafac $\AA$ (Labrafac Lipophile WL 1349) is composed of medium chains tiglycerides, caprylic/capric triglyceride and was obtained from Gattefossé (Saint Priest, France). Absorption and emission spectra were recorded on a Cary 400 Scan ultraviolet-visible spectrophotometer (Varian) and a FluoroMax-4 spectrofluorometer 
(Horiba Jobin Yvon) equipped with a thermostated cell compartment, respectively. For standard recording of fluorescence spectra, the emission was collected $10 \mathrm{~nm}$ after the excitation wavelength. All the spectra were corrected from wavelengthdependent response of the detector. Quantum yields were determined by comparison with a reference according to their excitation and emission wavelengths: Rhodamine $6 \mathrm{G}$ in wa$\operatorname{ter}^{65}$ was used as the reference for SMCy3 and SMCy3.5, DID in $\mathrm{MeOH}^{66}$ for SMCy5 and SMCy5.5, Rhodamine 800 in $\mathrm{EtOH}^{67}$ for SMCy7. For SMCy7.5, Rhodamine 800 and Indocyanine green in $\mathrm{MeOH}^{68}$ were used depending on the solvent.

\section{TPE measurements}

Two-photon absorption cross-section measurements were performed using Rhodamine B in methanol as a calibration standard according to the method of Webb et al..$^{69}$ Two-photon excitation was provided by an InSight DS + laser (Spectra Physics) with a pulse duration of $120 \mathrm{fs}$. The laser was focused with an achromatic lens $(\mathrm{f}=2 \mathrm{~cm}$ ) in a cuvette containing the dye (SMCy3: $6.04 \mu \mathrm{M}$, SMCy3.5: $2.08 \mu \mathrm{M}$, SMCy5: 1.06 $\mu \mathrm{M}$, SMCy5.5: $285 \mathrm{nM}$ ) in DMSO and the spectra were recorded with a fibered spectrometer (Avantes) by collecting the fluorescence emission at $90^{\circ}$ with a $20 \times$ Olympus objective .

\section{X-ray crystallography}

Single crystals of SMCy7 were obtained by solvent exchange method using DCM as solvent and cyclohexane as antisolvent. ${ }^{70} \mathrm{X}$-Ray diffraction data collection was carried out on a Bruker APEX II DUO Kappa-CCD diffractometer equipped with an Oxford Cryosystem liquid N2 device, using Mo-K $\alpha$ radiation $(\lambda=0.71073 \AA)$. The crystal-detector distance was $38 \mathrm{~mm}$. The cell parameters were determined $\left(A P E X 2\right.$ software) ${ }^{71}$ from reflections taken from tree sets of 12 frames, each at $10 \mathrm{~s}$ exposure. The structure was solved by Direct methods using the program SHELXS-2013. ${ }^{72}$ The refinement and all further calculations were carried out using SHELXL-2013. ${ }^{73}$ The H-atoms were included in calculated positions and treated as riding atoms using SHELXL default parameters. The non- $\mathrm{H}$ atoms were refined anisotropically, using weighted full-matrix least-squares on F2. A semiempirical absorption correction was applied using SADABS in APEX $2 ;^{71}$ transmission factors: Tmin/Tmax $=0.6697 / 0.7456$.

\section{Confocal imaging}

KB cells (ATCC@ CCL-17) were grown in minimum essential medium (MEM, Gibco-Invitrogen) with $10 \%$ fetal bovine serum (FBS, Lonza), 1\% non-essential amino acids (GibcoInvitrogen), 1\% MEM vitamin solution (Gibco-Invitrogen), $1 \%$ L-Glutamine (Sigma Aldrich) and $0.1 \%$ antibiotic solution (gentamicin, Sigma-Aldrich) at $37^{\circ} \mathrm{C}$ in humidified atmosphere containing $5 \% \mathrm{CO}_{2}$. Cells were seeded onto a chambered coverglass (IBiDi $\left.{ }^{\circledR}\right)$ at a density of $5 \times 10^{4}$ cells/well $24 \mathrm{~h}$ before the microscopy measurement. For imaging, the culture medium was removed and the attached cells were washed with Opti-MEM (Gibco-Invitrogen). Next, the cells were incubated in Opti-MEM with Hoechst $(5 \mu \mathrm{g} / \mathrm{mL})$ to stain the nuclei and in the presence of Nile Red or SMCy dyes $(0.5$ to $1 \mu \mathrm{M})$ for 3 $\mathrm{h}$, the living cells were washed three times with HBSS and visualized in HBSS or were fixed in 4\% PFA in HBSS for 5 minutes before being washed three times in HBSS. The images were processed with Icy software. ${ }^{74}$ The plasma membrane was stained with dSQ12S (200 nM) prior to imaging. ${ }^{55}$ The Pearson's correlation coefficient was measure with the Colocalization Studio plugin ${ }^{75}$ using Icy software.

\section{Cytotoxicity assay}

Cytotoxicity assay of the SMCy dyes was quantified by the MTT assay (3-(4,5-dimethylthiazol-2-yl)-2,5diphenyltetrazolium bromide). A total of $1 \times 10^{4} \mathrm{~KB}$ cells/well were seeded in a 96 -well plate $24 \mathrm{~h}$ prior to the cytotoxicity assay in Dulbecco's Modified Eagle Medium (Gibco Lifetechnologies -DMEM) complemented with $10 \%$ fetal bovine serum, Gentamicin $(100 \mu \mathrm{g} / \mathrm{mL})$, L-Glutamine $(2 \mathrm{mM})$, nonessential amino acids (1 mM), MEM vitamin solution $(1 \%)$ and were incubated in a $5 \% \mathrm{CO}_{2}$ incubator at $37^{\circ} \mathrm{C}$. After medium removal, an amount of $100 \mu \mathrm{L}$ DMEM containing $5 \mu \mathrm{M}$, $1 \mu \mathrm{M}$ or $0.2 \mu \mathrm{M}$ of $\mathrm{SMCy}$ (SMCy3, SMCy3.5, SMCy5, SMCy5.5, SMCy7 and SMCy7.5) was added to the KB cell and incubated for $3 \mathrm{~h}$ at $37^{\circ} \mathrm{C}\left(5 \% \mathrm{CO}_{2}\right)$. As control, for each 96-well plate, the cells were incubated with DMEM containing the same percentage of DMSO $(0,5 \% \mathrm{v} / \mathrm{v})$ as the solution with the tested dyes or with Triton $1 \%$ as a positive control of cytotoxicity. After $3 \mathrm{~h}$ of dye incubation, the medium was replaced by $100 \mu \mathrm{L}$ of a mix containing DMEM + MTT solution (diluted in PBS beforehand) and the cells were incubated for 4 $\mathrm{h}$ at $37^{\circ} \mathrm{C}$. Then, $75 \mu \mathrm{L}$ of the mix was replaced by $50 \mu \mathrm{L}$ of DMSO (100\%) and gently shaken for $15 \mathrm{~min}$ at room temperature in order to dissolve the insoluble purple formazan reduced in living cells. The absorbance at $540 \mathrm{~nm}$ was measured (absorbances of the dyes at $540 \mathrm{~nm}$ were taken into account). Each concentration of dye was tested in sextuplicate in 3 independant assays. For each concentration, we calculated the percentage of cell viability in reference of the control DMEM+ $0.5 \%$ DMSO.

\section{Tissue imaging}

C57BL6/J mice were maintained on a $12 \mathrm{~h}$ light-dark cycle with ad libitum access to food and water. All animal work was conducted following protocol approved by ethical committee. Adult C57BL6 mice were euthanized by $\mathrm{CO}_{2}$ administration . Liver and fat pads were immediately dissected and washed in PBS at $4^{\circ} \mathrm{C}$. The liver was sliced in $1 \mathrm{~mm}$ slices on a Leica Vibratome. Tissues were placed overnight at $4^{\circ} \mathrm{C}$ in $1 \mathrm{~mL}$ of freshly prepared solution of dye. Adipose tissue: SMCy3.5: 5 $\mu \mathrm{M}$, MemBright-488, $5 \mu \mathrm{M}$ and Hoechst: $5 \mu \mathrm{g} / \mathrm{mL}$ in PBS. Liver tissue: (SMCy5.5: $5 \mu \mathrm{M}$ and Hoechst: $5 \mu \mathrm{g} / \mathrm{mL}$ in PBS. The tissue samples were washed 3 times with PBS before being placed in a homemade glass chamber, allowing the imaging on both sides of the slides. Briefly a $1 \mathrm{~cm}$ diameter hole was breached in a glass slide thanks to a diamond drill bit. The $1 \mathrm{~mm}$ tissue slice was inserted in the hole, covered by a coverslip (170 nm, \#1.5) on each slide, and sealed with Picodent twinsil. The adipose tissue slices were imaged with a Leica DMi8 microscope equipped with a spinning disc CSU-X1. The microscopy settings were: Hoechst (ex $405 \mathrm{~nm}$, Em

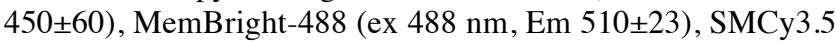
(ex $561 \mathrm{~nm}, \mathrm{Em} 590 \pm 35$ ). The images were acquired with 0.37 pixel width in XY and $0.5 \mu \mathrm{m}$ in $\mathrm{Z}$ with a PL APO 20x/0.75 oil immersion Leica objective. The images were processed with Icy software. For two-photon imaging see below. 


\section{Two-photon imaging}

Two-photon fluorescence microscopy imaging was performed on a TriMScope II (LaVision BioTec, Bielefeld, Germany) built on an Olympus BX51 microscope. The excitation source was a tunable InSight laser (Spectra Physics) (range $690-1300 \mathrm{~nm}$, repetition rate $80 \mathrm{MHz}$ ). For our experiments the excitation wavelength was fixed at $810 \mathrm{~nm}$. Each line was scanned twice (line average 2) with a speed of $0.4 \mu$ s per pixel using a 20X Plan Apo NA:1 water immersion objective, with working distance of $2 \mathrm{~mm}$ (Carl Zeiss, Germany). A z-stack of 66 images was aquired with a $\mathrm{z}$-step of $0.8 \mu \mathrm{m}$ for a total depth of $52 \mu \mathrm{m}$. The fluorescence signal was detected backwards with sensitive gallium arsenide phosphide detectors (GaAsp). We used bandpass filters for the detection; more precisely for the collagen fiber and the SHG signal 400-410 $\mathrm{nm}$, the Hoechst 435-485 $\mathrm{nm}$ and the SMCy5.5 655-685nm. The images were processed with Icy software.

\section{Lipid Droplets Exchange experiments}

$\mathrm{KB}$ cells were seeded on T-25 flask at a density of $1.5 \times 10^{6}$ cells before the day of the LDs staining. The next day the medium was removed, the adhered cells were rinsed with PBS 2 times. Then, the cells were separately incubated with SMCy3.5 or SMCy5.5 (1 $\mu \mathrm{M}$ in OptiMEM 0.5\%DMSO) at $37^{\circ} \mathrm{C}, 90 \%$ humidity, $5 \% \mathrm{CO}_{2}$ for $3 \mathrm{~h}$. After incubation the media containing the dyes were discharged, $\mathrm{KB}$ cells were rinsed with PBS 2 times, growth medium to insure a proper removal of the excess dyes and PBS again. Cells were trypsinised, centrifuged at $15000 \mathrm{rpm}$ for 3 minutes and the pellets of cells were resuspended in growth medium. The suspensions of cells were centrifuged again and cells were resuspended in the growth medium. Both fractions of cells were thoroughly mixed together in the same amount $\left(\sim 6 \times 10^{6}\right.$ in total). The cells were seeded onto a chambered coverglass (IBiDi) at a density of $1 \times 10^{5}$ cells/well. Prior to imaging, cells were incubated with Hoechst $(5 \mu \mathrm{g} / \mathrm{mL})$ for $15 \mathrm{~min}$ for nucleus staining. The cells were then fixed with PFA $4 \%$ for $5 \mathrm{~min}$ and washed 3 times with HBSS. Images were taken after $18 \mathrm{~h}$ and $48 \mathrm{~h}$ post cell adherence with a spinning-disk microscopy. For this purpose, Nikon Ti-E inverted microscope, equipped with CFI Plan Apo $\times 60$ oil (NA = 1.4) objective, X-Light spinning disk module (CresOptics) and a Hamamatsu Orca Flash 4 sCMOS camera, was used. The microscopy settings were: Hoechst (ex. $405 \mathrm{~nm}$, em. 510 $\pm 42 \mathrm{~nm}$ ), SMCy3.5 (ex. $532 \mathrm{~nm}$, em $600 \pm 25 \mathrm{~nm}$ ), SMCy5.5 (ex. $638 \mathrm{~nm}$, em. $705 \pm 36 \mathrm{~nm}$ ). The images were recorded using NIS Elements and then processed with Icy.

\section{ASSOCIATED CONTENT}

\section{Supporting Information}

Synthesis, protocols, characterizations and spectra are available in the supporting Information. The Supporting Information is available free of charge on the ACS Publications website.

\section{AUTHOR INFORMATION}

\section{Corresponding Author}

*mayeul.collot@unistra.fr

\section{Author Contributions}

The manuscript was written through contributions of all authors. / All authors have given approval to the final version of the manuscript.

\section{ACKNOWLEDGMENT}

We thank Romain Vauchelles for his assistance at the PIQ imaging platform and Bogdan Andreiuk for providing us with compound 1. We acknowledge the Service de Chimie Analytique (SCA) for LC-MS and RMN analyses. We also acknowledge the ImagoSeine core facility of the Institut Jacques Monod, members of IBiSA and the France-BioImaging infrastructure. This work was supported by ERC Consolidator grant BrightSens 648528, ANR BrightRiboProbes (ANR-16-CE11-0010) and ANR grant (ANR-10-INBS-04).

\section{ABBREVIATIONS}

LD: Lipid droplet; SMCy StatoMerocyanine; ORTEP: Oak Ridge Thermal Ellipsoid Plot; MTT: 3-(4,5-dimethylthiazol-2-yl)-2,5diphenyltetrazolium bromide); TPE: Two Photon Excitation, TPA: Two Photon Absorption; GM: Goeppert-Maye; PFA: paraformaldehyde. FRET: Förster resonance energy transfer. LDL: Low Density Lipoprotein. NMR: Nuclear Magnetic Resonance. ROI: Region Of Interest.

\section{REFERENCES}

(1) Farese, R. V.; Walther, T. C. Cell 2009, 139, 855-860.

(2) Martin, S.; Parton, R. G. Nat. Rev. Mol. Cell Biol. 2006, 7, $373-378$.

(3) Walther, T. C.; Jr, R. V. F. Annu. Rev. Biochem. 2012, 81, $687-714$

(4) Thiam, A. R.; Farese Jr, R. V.; Walther, T. C. Nat. Rev. Mol. Cell Biol. 2013, 14, 775-786.

(5) Zehmer, J. K.; Huang, Y.; Peng, G.; Pu, J.; Anderson, R. G. W.; Liu, P. Proteomics 2009, 9, 914-921.

(6) Blom, T.; Somerharju, P.; Ikonen, E. Cold Spring Harb. Perspect. Biol. 2011, 3.

(7) Olzmann, J. A.; Richter, C. M.; Kopito, R. R. Proc. Natl. Acad. Sci. 2013, 110, 1345-1350.

(8) Bozza, P. T.; Viola, J. P. B. Prostaglandins Leukot. Essent. Fat. Acids PLEFA 2010, 82, 243-250.

(9) Krahmer, N.; Farese, R. V.; Walther, T. C. EMBO Mol. Med. 2013, 5, 973-983.

(10) Herker, E.; Harris, C.; Hernandez, C.; Carpentier, A.; Kaehlcke, K.; Rosenberg, A. R.; Farese, R. V.; Ott, M. Nat. Med. 2010, 16, 1295-1298.

(11) Tirinato, L.; Pagliari, F.; Limongi, T.; Marini, M.; Falqui, A.; Seco, J.; Candeloro, P.; Liberale, C.; Di Fabrizio, E. Stem. Cells. Int. 2017, doi: $10.1155 / 2017 / 1656053$.

(12) Liu, Q.; Luo, Q.; Halim, A.; Song, G. Cancer Lett. 2017, 401 (Supplement C), 39-45.

(13) Abramczyk, H.; Surmacki, J.; Kopeć, M.; Olejnik, A. K.; Lubecka-Pietruszewska, K.; Fabianowska-Majewska, K. Analyst 2015, 140, 2224-2235.

(14) Lavis, L. D. Annu. Rev. Biochem. 2017, 86, 825-843.

(15) Zhu, H.; Fan, J.; Du, J.; Peng, X. Acc. Chem. Res. 2016, 49, 2115-2126.

(16) Yang, Y.; Zhao, Q.; Feng, W.; Li, F. Chem. Rev. 2013, 113, $192-270$.

(17) Kobayashi, H.; Ogawa, M.; Alford, R.; Choyke, P. L.; Urano, Y. Chem. Rev. 2010, 110, 2620-2640.

(18) Nadler, A.; Schultz, C. Angew. Chem. Int. Ed. 2013, 52, $2408-2410$ 
(19) Li, X.; Gao, X.; Shi, W.; Ma, H. Chem. Rev. 2014, 114, 590-659.

(20) Su, D.; Teoh, C. L.; Wang, L.; Liu, X.; Chang, Y.-T. Chem Soc. Rev. 2017, 46, 4833-4844.

(21) Klymchenko, A. S. Acc. Chem. Res. 2017, 50, 366-375.

(22) Greenspan, P.; Mayer, E. P.; Fowler, S. D. J. Cell Biol. 1985, 100, 965-973.

(23) Life Technologies https://www.thermofisher.com/.

(24) Spandl, J.; White, D. J.; Peychl, J.; Thiele, C. Traffic 2009, $10,1579-1584$

(25) Wang, Z.; Gui, C.; Zhao, E.; Wang, J.; Li, X.; Qin, A.; Zhao, Z.; Yu, Z.; Tang, B. Z. ACS Appl. Mater. Interfaces 2016, 8, 10193-10200.

(26) Sharma, A.; Umar, S.; Kar, P.; Singh, K.; Sachdev, M.; Goel, A. Analyst 2015, 141, 137-143.

(27) Appelqvist, H.; Stranius, K.; Börjesson, K.; Nilsson, K. P. R.; Dyrager, C. Bioconjug. Chem. 2017, 28, 1363-1370.

(28) Kang, M.; Gu, X.; Kwok, R. T. K.; Leung, C. W. T.; Lam,

J. W. Y.; Li, F.; Tang, B. Z. Chem. Commun. 2016, 52, 5957-5960.

(29) Jiang, M.; Gu, X.; Lam, J. W. Y.; Zhang, Y.; Kwok, R. T. K.; Wong, K. S.; Tang, B. Z. Chem. Sci. 2017, 8, 5440-5446.

(30) Gonçalves, M. S. T. Chem. Rev. 2009, 109, 190-212.

(31) Sun, W.; Guo, S.; Hu, C.; Fan, J.; Peng, X. Chem. Rev. 2016, 116, 7768-7817.

(32) Chan, J.; Dodani, S. C.; Chang, C. J. Nat. Chem. 2012, 4, 973-984.

(33) Kamada, K.; Namikawa, T.; Senatore, S.; Matthews, C.; Lenne, P.-F.; Maury, O.; Andraud, C.; Ponce-Vargas, M.; Le Guennic, B.; Jacquemin, D.; Agbo, P.; An, D. D.; Gauny, S. S.; Liu, X.; Abergel, R. J.; Fages, F.; D’Aléo, A. Chem. - Eur. J. 2016, 22, 52195232.

(34) Kim, E.; Felouat, A.; Zaborova, E.; Ribierre, J.-C.; Wu, J. W.; Senatore, S.; Matthews, C.; Lenne, P.-F.; Baffert, C.; Karapetyan, A.; Giorgi, M.; Jacquemin, D.; Ponce-Vargas, M.; Guennic, B. L.; Fages, F.; D'Aléo, A. Org. Biomol. Chem. 2016, 14, 1311-1324.

(35) Zhou, Y.; Chen, Y.-Z.; Cao, J.-H.; Yang, Q.-Z.; Wu, L.-Z.; Tung, C.-H.; Wu, D.-Y. Dyes Pigments 2015, 112, 162-169.

(36) Pfister, A.; Zhang, G.; Zareno, J.; Horwitz, A. F.; Fraser, C. L. ACS Nano 2008, 2, 1252-1258.

(37) Contreras, J.; Xie, J.; Chen, Y. J.; Pei, H.; Zhang, G.; Fraser, C. L.; Hamm-Alvarez, S. F. ACS Nano 2010, 4, 2735-2747.

(38) Kerr, C.; DeRosa, C. A.; Daly, M. L.; Zhang, H.; Palmer, G. M.; Fraser, C. L. Biomacromolecules 2017, 18, 551-561.

(39) G. Pitter, D. R.; S. Brown, A.; D. Baker, J.; N. Wilson, J. Org. Biomol. Chem. 2015, 13, 9477-9484.

(40) DeRosa, C. A.; Samonina-Kosicka, J.; Fan, Z.; Hendargo, H. C.; Weitzel, D. H.; Palmer, G. M.; Fraser, C. L. Macromolecules 2015, 48, 2967-2977.

(41) DeRosa, C. A.; Seaman, S. A.; Mathew, A. S.; Gorick, C. M.; Fan, Z.; Demas, J. N.; Peirce, S. M.; Fraser, C. L. ACS Sens. 2016, 1, 1366-1373.

(42) Wilson, J. N.; Wigenius, J.; Pitter, D. R. G.; Qiu, Y.; Abrahamsson, M.; Westerlund, F. J. Phys. Chem. B 2013, 117, 1200012006.

(43) Pitter, D. R. G.; Wigenius, J.; Brown, A. S.; Baker, J. D.; Westerlund, F.; Wilson, J. N. Org. Lett. 2013, 15, 1330-1333.

(44) Karpenko, I. A.; Niko, Y.; Yakubovskyi, V. P.; Gerasov, A. O.; Bonnet, D.; Kovtun, Y. P.; Klymchenko, A. S. J. Mater. Chem. C 2016, 4, 3002-3009.

(45) Easton, T. G.; Valinsky, J. E.; Reich, E. Cell 1978, 13, $475-486$.
(46) Zyabrev, K.; Doroshenko, A.; Mikitenko, E.; Slominskii, Y.; Tolmachev, A. Eur. J. Org. Chem. 2008, 2008, 1550-1558.

(47) Gerasov, A. O.; Shandura, M. P.; Kovtun, Y. P. Dyes Pigments 2008, 77, 598-607.

(48) Gerasov, A. O.; Shandura, M. P.; Kovtun, Y. P. Dyes Pigments 2008, 79, 252-258.

(49) Gerasov, A. O.; Zyabrev, K. V.; Shandura, M. P.; Kovtun, Y. P. Dyes Pigments 2011, 89, 76-85.

(50) Gieseking, R. L.; Mukhopadhyay, S.; Risko, C.; Marder, S. R.; Brédas, J.-L. Chem. Mater. 2014, 26, 6439-6447.

(51) Frischmann, P. D.; Würthner, F. Org. Lett. 2013, 15, 4674 4677

(52) Ozdemir, T.; Atilgan, S.; Kutuk, I.; Yildirim, L. T.; Tulek, A.; Bayindir, M.; Akkaya, E. U. Org. Lett. 2009, 11, 2105-2107.

(53) Ernst, L. A.; Gupta, R. K.; Mujumdar, R. B.; Waggoner, A. S. Cytometry 1989, 10, 3-10.

(54) A. Padilha, L.; Webster, S.; V. Przhonska, O.; Hu, H.; Peceli, D.; L. Rosch, J.; V. Bondar, M.; O. Gerasov, A.; P. Kovtun, Y.; P. Shandura, M.; D. Kachkovski, A.; J. Hagan, D.; Stryland, E. W. V. J. Mater. Chem. 2009, 19, 7503-7513.

(55) Collot, M.; Kreder, R.; Tatarets, A. L.; Patsenker, L. D.; Mely, Y.; Klymchenko, A. S. Chem. Commun. 2015, 51, 1713617139.

(56) Lavis, L. D. Biochemistry (Mosc.) 2017, 56 , 5165-5170.

(57) Lavis, L. D.; Raines, R. T. ACS Chem. Biol. 2014, 9, 855866.

(58) Helmchen, F.; Denk, W. Nat. Methods 2005, 2, 932-940.

(59) Svoboda, K.; Yasuda, R. Neuron 2006, 50, 823-839.

(60) Piston, D. W. Trends Cell Biol. 1999, 9, 66-69.

(61) Yao, S.; Belfield, K. D. Eur. J. Org. Chem. 2012, 2012, $3199-3217$.

(62) Mohler, W.; Millard, A. C.; Campagnola, P. J. Methods 2003, 29, 97-109.

(63) Chen, X.; Nadiarynkh, O.; Plotnikov, S.; Campagnola, P. J. Nat. Protoc. 2012, 7, 654-669.

(64) Smith, R. A. J.; Porteous, C. M.; Gane, A. M.; Murphy, M. P. Proc. Natl. Acad. Sci. 2003, 100, 5407-5412.

(65) Magde, D.; Rojas, G. E.; Seybold, P. G. Photochem. Photobiol. 1999, 70, 737-744.

(66) Texier, I.; Goutayer, M.; Da Silva, A.; Guyon, L.; Djaker, N.; Josserand, V.; Neumann, E.; Bibette, J.; Vinet, F. J. Biomed. Opt. 2009, 14, 054005-054005-11.

(67) Alessi, A.; Salvalaggio, M.; Ruzzon, G. J. Lumin. 2013, 134, 385-389.

(68) Benson, R.; Kues, H. Phys. Med. Biol. 1978, 23, 159-163.

(69) Albota, M. A.; Xu, C.; Webb, W. W. Appl. Opt. 1998, 37 , $7352-7356$.

(70) Spingler, B.; Schnidrig, S.; Todorova, T.; Wild, F. CrystEngComm 2012, 14, 751-757.

(71) "M86-E01078 APEX2 User Manual", Bruker AXS Inc., Madison, USA, 2006.

(72) Sheldrick, G. M. Acta Crystallogr. A 1990, 46, 467-473.

(73) Sheldrick, G. M. Acta Crystallogr. A 2008, 64, 112-122.

(74) Chaumont, F. de; Dallongeville, S.; Chenouard, N.; Hervé, N.; Pop, S.; Provoost, T.; Meas-Yedid, V.; Pankajakshan, P.; Lecomte, T.; Montagner, Y. L.; Lagache, T.; Dufour, A.; OlivoMarin, J.-C. Nat. Methods 2012, 9, nmeth.2075.

(75) Lagache, T.; Sauvonnet, N.; Danglot, L.; Olivo-Marin, J.C. Cytom. Part J. Int. Soc. Anal. Cytol. 2015, 87, 568-579. 